\title{
Monetary policy reaction function and external economic uncertainty: evidence from 30 selected countries
}

\author{
Pei-Tha Gan $^{a^{*},}$ Kok-Jing Yee ${ }^{a}$, Fatimah Salwa binti Abd. Hadia, and Norasibah binti Abdul Jalila
}

${ }^{a}$ Department of Economics, Faculty of Management and Economics, Universiti Pendidikan Sultan Idris (Sultan Idris Education University), 35900 Tanjong Malim, Perak, Malaysia

\section{CHRON I C L E}

\section{Article history:}

Received: March 18, 2019

Received in revised format: April

92019

Accepted: April 23, 2019

Available online:

April 24, 2019

Keywords:

Monetary policy reaction

External economic uncertainty

Panel unit root tests

Panel heterogeneous cointegra-

tion technique

\section{A B S T R A C T}

A noteworthy feature in the monetary policy decision making is that interest rate can play a significant role in addressing economic uncertainty. Although the empirical studies on monetary policy reaction function routinely include the output gap and the inflation, not many studies take into account the exchange rate uncertainty and terms of trade uncertainty. To overcome this shortcoming, this paper examines the monetary policy reaction function by including the external economic uncertainty. Based on 30 selected countries, the estimation is relaxed by using the panel heterogeneous cointegration technique. The findings suggest that (i) the interest rate can serve as an important instrument for the central bank policy decision making to combat the economic uncertainty arising from output, inflation, exchange rate and terms of trade (TOT), and (ii) the economic uncertainty (i.e., output uncertainty, inflation uncertainty, exchange rate uncertainty and TOT uncertainty) can serve as a useful information for monetary policy action to avoid and/or mitigate a negative impact of uncertainty.

\section{Introduction}

Exchange rate and terms of trade (TOT) ${ }^{1}$ can be significant in the monetary policy decision making. The changes in prices of foreign goods via exchange rate can induce a change in domestic inflation (Taylor, 2000). Undoubtedly, one cannot ignore the unknown change in the exchange rate for better monetary policy reaction to achieve a goal of low inflation level (Bianchi \& Deschamps, 2017). On the other hand, TOT remains significant in the open economy, in which a negative shock of TOT can induce a recovery in growth by depreciating the exchange rate (Funke et al., 2008). Because a reduce in TOT can cause a negative impact on output gap and inflation that eventually lead to a sluggish future economic growth, the TOT cannot be ignored in the monetary policy decision making (Fatima, 2010).

A noteworthy feature in the monetary policy decision making is that interest rate can play a significant role in addressing economic uncertainty (Bernanke, 2010). ${ }^{2}$ Although the empirical research on monetary

${ }^{1}$ Terms of trade refer to the ratio of an index of a country's export prices to an index of its import prices (Black et al., 2017)

${ }^{2}$ Economic uncertainty refers to unknown future economic events (Knight, 1921).

* Corresponding author. Tel: +017-7709689; Fax: +6015-48117295

E-mail address: gan.pt@fpe.upsi.edu.my (P.-T. Gan) 
policy reaction function routinely include the output gap and the inflation, not many studies take into account the external economic uncertainty, i.e., exchange rate uncertainty and terms of trade uncertainty (Note that variable in gap form - a deviation between actual value and potential/equilibrium value - can be considered as an uncertainty (Ben-Haim et al, 2017), and thus, one can consider output gap and the inflation gap as output uncertainty and inflation uncertainty, respectively). For instance, Smets (2002) argues that the presence of output uncertainty can possibly serve as a useful indicator for the monetary policymakers to achieve better economic performances. By using detrending methods, Orphanides and Norden (2002) suggest that the output uncertainty should be measured accurately to provide a reliable signal for monetary policy design. Mishkin (2002) finds that policymaker should focus on the inflation movement in order to reduce the output uncertainty using canonical model. Furthermore, Salunkhe and Patnaik (2017) use Granger causality test and structural vector autoregression to examine the relationship between interest rate and, output gap and inflation. Their finding concludes that output gap has a greater impact rather than inflation. On the other hand, Cioran (2014) finds that the interest rate tool can well control the inflation uncertainty by using a linear regression model. Some argue that policymaker has to strive to eliminate the public's expectations and control inflation uncertainty that can increase the economic activity and induce a good economic performance. By using a cross-sectional variance of point forecast, Glas and Hartmann (2016) find that the inflation uncertainty is an important indicator of monetary policy. Sauer and Bohara (1995) suggest that the use of anti-inflationary policy can keep inflation uncertainty at low level that may avoid a deficiency in economic growth. Therefore, it seems natural to examine external economic uncertainty that can improve the effectiveness of monetary policy.

The objective of this paper is to examine the monetary policy reaction function by including the external economic uncertainty, namely exchange rate uncertainty and TOT uncertainty, without neglecting the output gap (hereafter output uncertainty) and inflation (hereafter inflation uncertainty), such that (i) the interest rate can serve as an important instrument for the central bank policy decision making to combat the economic uncertainty arising from output, inflation, exchange rate and TOT, and (ii) the economic uncertainty (i.e., output uncertainty, inflation uncertainty, exchange rate uncertainty and TOT uncertainty) can serve as a useful information for monetary policy action to avoid and/or mitigate a negative impact of uncertainty. This paper includes a sample of 30 selected countries, namely, Argentina, Australia, Brazil, Canada, China, Colombia, Czech Republic, Denmark, Finland, Hong Kong, Indonesia, Ireland, Italy, Japan, Malaysia, Mexico, New Zealand, Philippines, Poland, Russia, Singapore, South Africa, South Korea, Spain, Sweden, Switzerland, Thailand, Turkey, United Kingdom and United States to serve as a platform to test the external economic uncertainty in monetary policy reaction function. By using the panel heterogeneous cointegration test proposed by Pesaran et al. (1999), this paper examines the augmented Taylor rule by analyzing both the long-run and the short-run relationships between interest rate policy and its determinants (i.e., output uncertainty, inflation uncertainty, exchange rate uncertainty and TOT uncertainty).

The remainder of the paper is arranged as follows. Section 2 describes the theoretical model and methodology. The data and the empirical results are discussed in Section 3. Section 4 concludes the paper.

\section{Theoretical model and methodology}

\subsection{Theoretical model}

This paper uses the monetary policy reaction function proposed by Taylor (1993). Among others, it is also used by Christiano and Gust (1999), Sturm and Haan (2011) and Kuper (2018) (Note that the economic uncertainty variables are in gap forms, in which, is the deviations of the actual value and potential value/equilibrium value). The standard Taylor rule model can be described as follows: 


$$
r_{g}=f(\underbrace{y_{g}}_{+}, \underbrace{\pi_{g}}_{+}) \text {, }
$$

where, $r_{g}$ implies the interest rate gap, $y_{g}$ implies the output uncertainty and $\pi_{g}$ implies inflation uncertainty. The positive sign shows that the interest rate gap is positively related to output uncertainty and inflation uncertainty. In line with the hypothesis specified in this paper, an augmented Taylor rule can be explained as follows:

$$
r_{g}=f(\underbrace{y_{g}}_{+}, \underbrace{\pi_{g}}_{+}, \underbrace{e_{g}}_{-}, \underbrace{t o t_{g}}_{-}) \text {, }
$$

where, $e_{g}$ and tot $_{g}$ represents exchange rate uncertainty and terms of trade uncertainty, respectively. The negative sign shows that the interest rate gap is negatively related to exchange rate uncertainty and TOT uncertainty. The theoretical model for the augmented Taylor rule in this paper is as follows:

$$
r_{g_{t}}=\beta_{1} y_{g_{t-1}}+\beta_{2} \pi_{g_{t-1}}-\beta_{3} e_{g_{t-1}}-\beta_{4} \operatorname{tot}_{g_{t-1}}+\varepsilon_{t}
$$

where, the parameters of $\beta_{1}$ and $\beta_{2}$ are positive and parameters of $\beta_{3}$ and $\beta_{4}$ are negative. Equation 3 is the augmented Taylor rule model with certain modifications from the standard Taylor rule model to address the economic uncertainty in the terms of gap; where, $g$ implies gap and $\varepsilon_{t}$ represents error term. From the Equation 3, output uncertainty and inflation uncertainty shows positive signs suggest that the monetary policymakers can counter the problem of increasing output uncertainty and inflation uncertainty by raising the interest rate gap in order to stabilise the output uncertainty and inflation uncertainty. As for the exchange rate uncertainty and TOT uncertainty that shows negative signs implies that monetary policymakers suggest lowering the level of interest rate gap to maintain the level of exchange rate uncertainty and, at the same time, to improve the TOT uncertainty.

\subsection{Empirical Methodology}

This subsection presents the panel heterogeneous cointegration approach proposed by Pesaran et al. (1999) that used to estimate the theoretical model specified in subsection 2.1. This approach is also known as the panel autoregressive distributed lag (ARDL). Although the aim of this approach is for the long-run relationship determination, it can also be useful for short-run relationship determination. The inputs for panel ARDL are specified in the following panel error correction model (ECM) in Eq. (4).

$$
\begin{gathered}
\Delta r_{g_{t}}=\alpha_{i}+\sum_{j=1}^{p-1} \hat{\gamma}_{i_{j}} \Delta r_{g_{i, t-j}}+\sum_{j=1}^{q-1} \hat{\gamma}_{1 i_{j}} \Delta y_{g_{i, t-j}}+\sum_{j=1}^{q-1} \hat{\gamma}_{2 i_{j}} \Delta \pi_{g_{i, t-j}}+\sum_{j=1}^{q-1} \hat{\gamma}_{i 3_{j}} \Delta e_{g_{i, t-j}}+\sum_{j=1}^{q-1} \hat{\gamma}_{4 i_{j}} \Delta t o t_{g_{i, t-j}} \\
+\hat{\beta}_{i}\left(\Delta r_{g_{i, t-1}}-\hat{\delta}_{1 i} y_{g_{i t}}-\hat{\delta}_{2 i} \pi_{g_{i t}}-\hat{\delta}_{3 i} e_{g_{i t}}-\hat{\delta}_{4 i} t o t_{g_{i t}}\right)+\mu_{i}+\varepsilon_{i t}
\end{gathered}
$$

where, $\Delta$ represents the first difference, $r_{g}$ represents the interest rate gap, $y_{g}$ represents the output uncertainty, $\pi_{g}$ represents the inflation uncertainty, $e_{g}$ represents the exchange rate uncertainty, tot $_{g}$ represents the terms of trade uncertainty, $\hat{\beta}_{i}$ denotes the error correction coefficient, $\delta$ denotes the long-run coefficient, $\mu_{i}$ denotes the group-specific effect, $i=1,2,3, \ldots, N$ denotes the number of countries and $t=1,2,3, \ldots, T$ denotes the number of times. The mean group (MG) estimator and pooled mean group (PMG) estimator for Equation 4 is as follows:

$$
\begin{aligned}
& \hat{\theta}_{M G}=\frac{1}{N} \sum_{i=1}^{N} \hat{\theta}_{i}, \hat{\varphi}_{M G}=\frac{1}{N} \sum_{i=1}^{N} \hat{\varphi}_{i}, \hat{\lambda}_{M G}=\frac{1}{N} \sum_{i=1}^{N} \hat{\lambda}_{i} \\
& \hat{\theta}_{P M G}=\frac{1}{N} \sum_{i=1}^{N} \hat{\theta}_{i}, \hat{\varphi}_{P M G}=\hat{\varphi}_{i} \beta_{i}, \hat{\lambda}_{P M G}=\frac{1}{N} \sum_{i=1}^{N} \hat{\lambda}_{i}
\end{aligned}
$$


From the panel heterogeneous cointegration approach model, the MG estimator only takes into account of the mean of the parameters and estimate different regression for each group (Papageorgiou et al., 2016). On the other hand, the PMG estimator considers the combination of the pooling and averaging coefficients.

\section{Data and empirical results discussion}

\subsection{Data description}

This section describes the database in further detail for this paper. This paper uses quarterly basis data for the period from year 1995 quarter one to year 2018 quarter one based on a sample of 30 countries, namely, Argentina, Australia, Brazil, Canada, China, Colombia, Czech Republic, Denmark, Finland, Hong Kong, Indonesia, Ireland, Italy, Japan, Malaysia, Mexico, New Zealand, Philippines, Poland, Russia, Singapore, South Africa, South Korea, Spain, Sweden, Switzerland, Thailand, Turkey, United Kingdom and United States. Variables taken for this study are the interest rate gap $\left(r_{g}\right)$, the output uncertainty $\left(y_{g}\right)$, the inflation uncertainty $\left(\pi_{g}\right)$, the exchange rate uncertainty $\left(e_{g}\right)$, and terms of trade uncertainty $\left(\right.$ tot $\left._{g}\right)$. As mentioned in Section 1, one can use variable in gap form and uncertainty interchangeably as a deviation between actual value and potential/equilibrium value. The potential/equilibrium value can be calculated via Hodrick-Prescott (HP) filter with the value of 1600 for smoothing parameter. The sources of the data are taken from the International Monetary Fund (IMF), International Financial Statistics (IFS) and Bank for International Settlements Statistic (BIS Statistics).

In this study, the effective exchange rates index is used as a proxy of the exchange rate variable. The output variable conducted in this study is also known as the Gross Domestic Product and the money market rate is used to serve as the monetary policy variable. As for the TOT variable, it implies a relative export prices to an import prices. The interest rate gap is the difference between the real interest rate and its potential. To obtain the output uncertainty, the logged actual real output minus the logged potential real output, which is then multiplied by 100 . The inflation uncertainty is the difference between the inflation rate and its potential; the inflation rate is obtained from the first difference of the log of the consumer price index level. The exchange rate uncertainty is the difference between the real effective exchange rate and its potential, which is then multiplied by 100 . The TOT uncertainty is the difference between the TOT and its potential, which is then multiplied by 100 .

\subsection{Empirical Results}

Prior to the panel heterogeneous cointegration approach testing procedure, this paper begins with the panel unit root tests, namely, Levin, Lin and Chu (LLC) test, Im, Pesaran and Shin (IPS) test and Maddala and $\mathrm{Wu}(\mathrm{MW})$ test which are applied to test the stationarity of the variables. Table 1 shows the results of the panel unit root tests for interest rate gap $\left(r_{g_{t}}\right)$, output uncertainty $\left(y_{g_{t}}\right)$, inflation uncertainty $\left(\pi_{g_{t}}\right)$, exchange rate uncertainty $\left(e_{g_{t}}\right)$ and TOT uncertainty $\left(t_{0} t_{g_{t}}\right)$. The results reveal that all of the variables for 30 countries are stationary, in other words, the variables are integrated of order zero, $I(0)$. We then examine the long-run relationship between the monetary policy and its determinants (i.e., $y_{g_{t}}, \pi_{g_{t}}, e_{g_{t}}$, tot $_{g_{t}}$ ) based on 30 countries by using the panel heterogeneous cointegration approach. The Hausman (1978) test is used to determine the right model, i.e., do not reject the null hypothesis which indicates there is homogeneity; the test suggests that the PMG estimation is more appropriate compared to the MG estimation. Table 2 discusses the results of panel heterogeneous cointegration approach for the augmented Taylor rule model by using the quarterly basis data from year 1995 quarter one to year 2018 quarter one based on a sample of 30 countries. The Hausman test statistic of 1.34 ( $p$-value of 0.8552 ) impose that PMG estimates better results compared to MG estimate. The long-run coefficients of the PMG estimates that all variables are statistically significant but only certain determinants show the correct expected signs, in which, the coefficient of the output uncertainty, $y_{g_{t}}$ is 0.0348 , the coefficient of 
inflation uncertainty, $\pi_{g_{t}}$ is -1.2420 , the coefficient of exchange rate uncertainty, $e_{g_{t}}$ is -0.0138 and the coefficient of terms of trade uncertainty, tot $_{g_{t}}$ is 0.0291 . The error correction coefficient show that the value is in negative sign (-0.2239) and is significantly different from zero. Thus, we can conclude that the monetary policy has long-run relationships with output uncertainty and exchange rate uncertainty only whereas inflation uncertainty and TOT uncertainty did not show the correct expected signs even though significant. Moreover, the results of average short-run coefficients are significant; the results also discover that the average short-run coefficient of past interest rate gap is significant. The results of individual countries are presented in Appendix A, Table A.1 (Note that only PMG results are presented in the table because the PMG results are more favorable compared to MG results; only significant and correct expected sign variables are reported in the table). From Table A.1, the results show that most of the short-run coefficients are statistically significant.

Table 1

Panel unit root tests

\begin{tabular}{|c|c|c|c|c|c|}
\hline Variables & $r_{a_{t}}$ & $y_{a_{t}}$ & $\pi_{a_{t}}$ & $e_{a_{t}}$ & $t^{t o t} t_{q_{t}}$ \\
\hline \multicolumn{6}{|l|}{ LLC test } \\
\hline Level & $-3.6297 * * *$ & $-8.2062 * * *$ & $-44.7466 * * *(2)$ & $-2.56937 * * *(2)$ & $-3.1003^{* * *}$ (3) \\
\hline First Difference & $-19.9304 * * *(2)$ & $-19.9304 * * *(2)$ & $-3.6104 * * *$ & $-13.4082 * * *(3)$ & $-34.0842 * * *(2)$ \\
\hline Decision & $I(0)$ & $I(0)$ & $I(0)$ & $I(0)$ & $I(0)$ \\
\hline \multicolumn{6}{|l|}{ IPS test } \\
\hline Level & $-10.7644 * * *(3)$ & $-4.8297 * * *$ & $-14.9389 * * *(3)$ & $-13.0402 * * *(3)$ & $-10.0194 * * *(3)$ \\
\hline First Difference & $-21.8426 * * *(5)$ & $-18.7296 * * *(3)$ & $-19.7141 * * *(9)$ & $-20.7121 * * *(5)$ & $-23.7628 * * *(4)$ \\
\hline Decision & $I(0)$ & $I(0)$ & $I(0)$ & $I(0)$ & $I(0)$ \\
\hline \multicolumn{6}{|l|}{ MW test } \\
\hline Level & $235.139 * * *(3)$ & $169.384 * * *(10)$ & $163.985 * * *(17)$ & $176.255^{* * *}(10)$ & $132.726 * * *(15)$ \\
\hline First Difference & $366.373 * * *(13)$ & $197.989 * * *(17)$ & $367.212 * * *(15)$ & $290.509 * * *(15)$ & $462.228^{* * *}(10)$ \\
\hline Decision & $I(0)$ & $I(0)$ & $I(0)$ & $I(0)$ & $I(0)$ \\
\hline
\end{tabular}

Table 2

Estimations results of panel error correction model (ECM) for monetary policy reaction function using the augmented Taylor rule model

\begin{tabular}{|c|c|c|c|c|c|c|c|c|}
\hline \multirow{2}{*}{$\begin{array}{c}\text { ARDL } \\
(3,5,10,16,18)\end{array}$} & \multicolumn{3}{|c|}{ MG estimates } & \multicolumn{3}{|c|}{ PMG estimates } & \multicolumn{2}{|c|}{ Hausman Test } \\
\hline & Coef. & Std. err. & t-ratio & Coef. & Std. err. & t-ratio & $\mathrm{H}$ & p-value \\
\hline \multicolumn{9}{|c|}{ Long-run coefficients } \\
\hline$y_{g_{t}}$ & -0.0584 & 0.2623 & -0.2226 & 0.0348 & 0.0048 & $7.2500^{* * *}$ & 1.34 & 0.8552 \\
\hline$\pi_{g_{t}}$ & -1.2245 & 1.7840 & -0.6864 & -1.2420 & 0.1073 & $-11.5750 * * *$ & & \\
\hline$e_{g_{t}}$ & -0.0872 & 0.1922 & -0.4537 & -0.0138 & 0.0030 & $-4.6000 * * *$ & & \\
\hline $\operatorname{tot}_{g_{t}}$ & -0.2756 & 0.2504 & -1.1006 & 0.0291 & 0.0043 & $6.7674 * * *$ & & \\
\hline \multicolumn{9}{|c|}{ Error-correction coefficient } \\
\hline $\mathrm{EC}$ & -0.5738 & 0.1358 & -4.2253 & -0.2239 & 0.0567 & $-3.9489 * * *$ & & \\
\hline \multicolumn{9}{|c|}{ Short-run coefficients } \\
\hline$r_{g_{t}}$ & & & & 0.1516 & 0.0867 & $1.7486^{*}$ & & \\
\hline \multirow[t]{3}{*}{$y_{g_{t}}$} & & & & 0.0714 & 0.0250 & $2.8560 * * *$ & & \\
\hline & & & & 0.0598 & 0.0350 & $1.7086^{*}$ & & \\
\hline & & & & 0.0900 & 0.0545 & $1.6514 *$ & & \\
\hline$\pi_{g_{t}}$ & & & & 0.4276 & 0.1739 & $2.4589 * *$ & & \\
\hline & & & & 0.2422 & 0.1394 & $1.7374 *$ & & \\
\hline$e_{g_{t}}$ & -0.0248 & 0.0140 & $1.7714 *$ & -0.0343 & 0.0190 & $-1.8053^{*}$ & & \\
\hline $\operatorname{tot}_{g_{t}}$ & & & & -0.0219 & 0.0130 & $-1.6846^{*}$ & & \\
\hline
\end{tabular}

Notes: The $* * *, * *$ and $*$ denotes the significance level at $1 \%, 5 \%$ and $10 \%$, respectively. The lag length is selected based on the Schwarz Info Criterion (SIC) by using the sample period from year 1995 quarter one until year 2018 quarter one.

To determine the augmented Taylor rule model is meaningful, this paper examines the standard Taylor rule model to show its consistency with the textbook discussion; i.e., the standard Taylor rule model does not include exchange rate uncertainty and TOT uncertainty. Table 3 shows the results of panel error correction model (ECM) for the standard Taylor rule model from the first quarter of year 1995 until the first quarter of year 2018 based on a sample of 30 countries. The Hausman test statistic of 1.87 ( $p$-value of 0.3930 ) suggest that estimation of PMG is better than the estimation of MG. The long-run coefficients 
of the PMG estimates shows that output uncertainty is statistically significant and shows the correct expected sign compared to inflation uncertainty that shows statistically insignificant and incorrect expected signs, in which, the coefficient of output uncertainty, $y_{g_{t}}$ is 0.0984 and the coefficient of inflation uncertainty, $\pi_{g_{t}}$ is -0.0458 . The error correction coefficient show that the value is in negative sign (0.3185 ) and is significantly different from zero. Hence, we can only conclude that the long-run relationship only exist between interest rate gap and output gap but not inflation gap. On the other hand, the results of average short-run coefficients are statistically significant and have the correct signs; the results also discover that the average short-run coefficient of past interest rate gap is significant. The results of individual countries are presented in Appendix A, Table A.2 (Note that only PMG results are presented in the table because the PMG results are more favorable compared to MG results; only significant and correct expected sign variables are reported in the table). From Table A.2, the results show that most of the short-run coefficients are statistically significant.

\section{Table 3}

Estimations results of panel error correction model (ECM) for monetary policy reaction function using the standard Taylor rule model

\begin{tabular}{|c|c|c|c|c|c|c|c|c|}
\hline \multirow{2}{*}{$\begin{array}{c}\text { ARDL } \\
(3,5,10)\end{array}$} & \multicolumn{3}{|c|}{ MG estimates } & \multicolumn{3}{|c|}{ PMG estimates } & \multicolumn{2}{|c|}{ Hausman Test } \\
\hline & Coef. & Std. err. & t-ratio & Coef. & Std. err. & t-ratio & $\mathrm{H}$ & $\mathrm{p}$-value \\
\hline \multicolumn{9}{|c|}{ Long-run coefficients } \\
\hline$y_{g_{t}}$ & 0.4405 & 0.2670 & $1.6498 * * *$ & 0.0984 & 0.0119 & $8.2689 * * *$ & 1.87 & 0.3930 \\
\hline$\pi_{g_{t}}$ & 4.3325 & 5.0351 & 0.8605 & -0.0458 & 0.2159 & -0.2121 & & \\
\hline \multicolumn{9}{|c|}{ Error-correction coefficient } \\
\hline $\mathrm{EC}$ & -0.3190 & 0.0280 & $-11.3929 * * *$ & -0.3185 & 0.0392 & $-8.1250 * * *$ & & \\
\hline \multicolumn{9}{|c|}{ Short-run coefficient } \\
\hline$r_{g_{t}}$ & 0.2647 & 0.0543 & $4.8748 * * *$ & 0.3158 & 0.0408 & $7.740 * * *$ & & \\
\hline & 0.0939 & 0.0226 & $4.1549 * * *$ & 0.1002 & 0.0256 & $3.914 * * *$ & & \\
\hline$y_{g_{t}}$ & & & & 0.0229 & 0.0131 & $1.7481^{*}$ & & \\
\hline$\pi_{g_{t}}$ & 0.6763 & 0.3184 & $2.1241 * *$ & 0.3246 & 0.0983 & $3.3021 * * *$ & & \\
\hline & 0.3474 & 0.2053 & $1.6922 *$ & 0.1389 & 0.0722 & $1.9238^{*}$ & & \\
\hline & 0.2250 & 0.1056 & $2.1307 * *$ & 0.1069 & 0.0601 & $1.7787 *$ & & \\
\hline & 0.1308 & 0.0616 & $2.1234^{* *}$ & 0.1661 & 0.0623 & $2.6661 * * *$ & & \\
\hline & & & & 0.0878 & 0.0365 & $2.4055^{* *}$ & & \\
\hline
\end{tabular}

Notes: The $* * *, * *$ and $*$ denotes the significance level at $1 \%, 5 \%$ and $10 \%$, respectively. The lag length is selected based on the Schwarz Info Criterion (SIC) by using the sample period from year 1995 quarter one until year 2018 quarter one.

The following findings can be drawn from the above analysis. First, the results of monetary policy reaction function of an augmented Taylor rule show that the existence of long-run relationship between interest rate policy and output uncertainty, inflation uncertainty, exchange rate uncertainty, and TOT uncertainty. The deviation from long-run equilibrium influences the short-run dynamics of the variables. Second, a comparison result of monetary policy reaction function between the augmented Taylor rule and the standard Taylor rule reveals that the roles of exchange rate uncertainty and TOT uncertainty cannot be ignored in the monetary policy. Third, the results indicate that the past influence of interest rate gap is an uncertainty that cannot be ignored at least in the short-run. The policy implications propose that (i) the interest rate can serve as an important instrument for the central bank policy decision making to combat the economic uncertainty arising from output, inflation, exchange rate and TOT, and (ii) the economic uncertainty (i.e., output uncertainty, inflation uncertainty, exchange rate uncertainty and TOT uncertainty) can serve as a useful information for monetary policy action to avoid and/or mitigate a negative impact of uncertainty.

\section{Conclusions}

The objective of this paper was to examine the monetary policy reaction function by including the external economic uncertainty, namely exchange rate uncertainty and TOT uncertainty, without neglecting the output uncertainty and inflation uncertainty. The study has been carried out by using 30 countries. 
The results obtained from the panel heterogeneous cointegration method suggest that (i) the interest rate can serve as an important instrument for the central bank policy decision making to combat the economic uncertainty arising from output, inflation, exchange rate and TOT, and (ii) the economic uncertainty (i.e., output uncertainty, inflation uncertainty, exchange rate uncertainty and TOT uncertainty) can serve as a useful information for monetary policy action to avoid and/or mitigate a negative impact of uncertainty. This study has several limitations. First, this paper only relies on a sample of 30 countries, future researchers can increase the number of countries to strengthen the existence hypothesis proposed in this paper. Second, further researchers can extend the scope of study by including other variables (i.e., capital flows, international reserves, foreign price level, stock prices, and oil prices). Third, future researches may consider carrying out the same issue with a longer period of time series and testing the model by using different methodology to obtain better results.

\section{Acknowledgements}

This research work is supported by the FRGS grant (No. 2016-0214-106-41) supported by the Ministry of Education and Malaysia and Research Management and Innovation Centre, Sultan Idris Education University.

\section{References}

Falahi, M. A., \& Hajamini, M. (2015). Relationship between Inflation and Inflation Uncertainty in Iran: An Application of SETAR-GARCH Model. Journal of Money and Economy, 10(2), 69-91.

Ben-Haim, Y., Demertzis, M., Den End, V., \& Willem, J. (2017). Fundamental uncertainty and unconventional monetary policy: an info-gap approach. Bruegel Working Paper Issue 1/2017.

Bernanke, B. S. (2010). Implications of the financial crisis for economics: a speech at the Conference Co-sponsored by the Center for Economic Policy Studies and the Bendheim Center for Finance, Princeton University, Princeton, New Jersey, September 24, 2010 (No. 544).

Bianchi, P., \& Deschamps, B. (2018). The effectiveness of exchange-rate-based monetary policy: evidence from survey data. Applied Economics Letters, 25(18), 1261-1265.

Black, J., Hashimzade, N., \& Myles, G. (2017). A Dictionary of Economics. United Kingdom: Oxford University Press.

Christiano, L. J., \& Gust, C. J. (1999). Taylor rules in a limited participation model. De Economist, 147(4), 437-460.

Cioran, Z. (2014). Monetary policy, inflation and the causal relation between the inflation rate and some of the macroeconomic variables. Procedia Economics and Finance, 16, 391-401.

Fatima, N. (2010). Analysing the terms of trade: effect for Pakistan (PIDE Working Papers No. 2010:59). Islamabad: Pakistan Institute of Development Economics.

Funke, N., Granziera, E., \& Imam, P. (2008). Terms of trade shocks and economic recovery (IMF Working Paper WP/08/36). Washington: International Monetary Fund.

Gan, P. T. (2014). The optimal economic uncertainty index: A grid search application. Computational Economics, 43(2), 159-182.

Glas, A. and Hartmann, M. (2016). Inflation uncertainty, disagreement, and monetary policy: Evidence from the ECB survey of professional forecasters. Journal of Empirical Finance, 39, 215-228.

Hausman, J. A. (1978). Specification Tests in Econometric. Econometrica, 46(6), 1251-1271.

Knight, F. H. (1921). Risk, uncertainty and profit. Boston: Mifflin.

Kuper, G. H. (2018). The powers that are: central bank independence in the Greenspan era. Empirical Economics, 54, 485-499

Mishkin, F. S. (2002). The role of output stabilization in the conduct of monetary policy (NBER Working Paper No. 9291). MA: National Bureau of Economic Research.

Orphanides, A., \& Norden, S. V. (2002). The unreliability of output-gap estimates in real time. The Review of Economics and Statistics, 84(4), 569-583. 
Papageorgiou, T., Michaelides, P. G. and Tsionas, E. G. (2016). Business cycle determinants and fiscal policy: a panel ARDL approach for EMU. The Journal of Economic Asymmetries, 13, 57-68.

Pesaran, M. H., Shin, Y., \& Smith, R. P. (1999). Pooled mean group estimation of dynamic heterogeneous panels. Journal of the American Statistical Association, 94(446), 621-634.

Salunkhe, B., \& Patnaik, A. (2017). The impact of monetary policy on output and inflation in India: a frequency domain analysis. Economic Annals, 62(212), 113-154.

Sauer, C., \& Bohara, A. K. (1995). Monetary policy and inflation uncertainty in the United States and Germany. Southern Economic Journal, 62(1), 139-163.

Smets, F. (2002). Output gap uncertainty: does it matter for the Taylor rule?. Empirical Economics, 27, 113-129.

Sturm, J. E., \& Haan, J. D. (2011). Does central bank communication really lead to better forecast of policy decisions? New evidence based on a Taylor rule model for the ECB. Review of World Economics, 147, 41-58.

Taylor, J. B. (1993). Discretion versus policy rules in practice. Carnigie-Rochester Conference Series on Public Policy, 39, 195-214.

Taylor, J. B. (2000). Alternative views of the monetary transmission mechanism: What difference do they make for monetary policy?. Presented at the Central Bank of Chile.

\section{Appendix A}

\section{Table A.1}

Estimation of PMG results for 30 countries, individually, from year 1995 quarter one to year 2018 quarter one using augmented Taylor rule model

\begin{tabular}{|c|c|c|c|c|c|c|}
\hline \multirow[t]{2}{*}{ Countries } & \multicolumn{6}{|c|}{ Variables } \\
\hline & $r_{g_{t}}$ coef. $^{\mathrm{b}}$ & $y_{g_{t}}$ coef. $^{\mathrm{b}}$ & $\pi_{g_{t}}$ coef. $^{\mathrm{b}}$ & $e_{g_{t}}$ coef. $^{\mathrm{b}}$ & tot $_{g_{t}}$ coef. $^{\mathrm{b}}$ & EC coef. \\
\hline \multirow[t]{5}{*}{ Argentina } & $1.139[1]^{* * *}$ & $1.003[2]^{* * *}$ & $1.765[0]^{* *}$ & $-0.479[5] * *$ & $-0.177[15]^{* * *}$ & $-1.512 * * *$ \\
\hline & & $1.132[3] * * *$ & $2.019[1]^{* *}$ & $-0.164[16]^{*}$ & $-0.159[16]^{* * *}$ & \\
\hline & & & $3.209[3]^{* * *}$ & & & \\
\hline & & & $1.837[7]^{* *}$ & & & \\
\hline & & & $1.788[8]^{* *}$ & & & \\
\hline \multirow[t]{11}{*}{ Australia } & $0.395[1]^{* * *}$ & $0.0387[0]^{* *}$ & $0.626[1]^{* * *}$ & $-0.008[5]^{* *}$ & $-0.018[0]^{* * *}$ & -0.0243 \\
\hline & & $0.022[2]^{* *}$ & $0.210[5]^{*}$ & $-0.030[9]^{* * *}$ & $-0.009[2]^{* * *}$ & \\
\hline & & $0.0237[3]^{*}$ & $0.103[6]^{*}$ & & $-0.017[3]^{* * *}$ & \\
\hline & & $0.025[5]^{*}$ & $0.166[7]^{* * *}$ & & $-0.014[4]^{* * *}$ & \\
\hline & & & $0.202[8]^{* * *}$ & & $-0.007[5]^{* *}$ & \\
\hline & & & $0.277[9]^{* * *}$ & & $-0.018[8]^{* * *}$ & \\
\hline & & & $0.203[10]^{* * *}$ & & $-0.024[9]^{* * *}$ & \\
\hline & & & & & $-0.016[12]^{* * *}$ & \\
\hline & & & & & $-0.019[14] * * *$ & \\
\hline & & & & & $-0.007[16]^{* * *}$ & \\
\hline & & & & & $-0.006[17]^{* *}$ & \\
\hline \multirow[t]{11}{*}{ Brazil } & $0.480[1]^{* * *}$ & $0.210[0] * * *$ & $1.454[2] * * *$ & $-0.039[0] * * *$ & $-0.053[2]^{* * *}$ & 0.069 \\
\hline & & $0.245[1] * * *$ & $0.195[7]^{*}$ & $-0.079[1]^{* * *}$ & $-0.027[7]^{* * *}$ & \\
\hline & & $0.121[2]^{* * *}$ & & $-0.036[3]^{* * *}$ & $-0.042[8]^{* * *}$ & \\
\hline & & & & $-0.028[4]^{* *}$ & $-0.064[13]^{* * *}$ & \\
\hline & & & & $-0.056[5]^{* * *}$ & $-0.022[14] * * *$ & \\
\hline & & & & $-0.052[6]^{* * *}$ & $-0.032[17] * * *$ & \\
\hline & & & & $-0.047[7]^{* * *}$ & $-0.036[18]^{* * *}$ & \\
\hline & & & & $-0.083[9] * * *$ & & \\
\hline & & & & $-0.114[10]^{* * *}$ & & \\
\hline & & & & $-0.052[13]^{* * *}$ & & \\
\hline & & & & $-0.035[14]^{* * *}$ & & \\
\hline \multirow[t]{5}{*}{ Canada } & $0.414[1]^{* * *}$ & $0.114[0]^{* * *}$ & $0.996[1]^{* * *}$ & $-0.030[2] * * *$ & $-0.021[10]^{* * *}$ & $-0.154 * * *$ \\
\hline & $0.430[2]^{* * *}$ & $0.048[1]^{*}$ & $0.935[2]^{* * *}$ & $-0.041[3]^{* * *}$ & $-0.051[11]^{* * *}$ & \\
\hline & $0.295[3]^{* * *}$ & & $1.111[3]^{* * *}$ & $-0.019[16]^{* *}$ & $-0.036[12]^{* * *}$ & \\
\hline & & & $0.863[4]^{* * *}$ & & $-0.013[17]^{* *}$ & \\
\hline & & & $0.801[5]^{* * *}$ & & & \\
\hline
\end{tabular}




\begin{tabular}{|c|c|c|c|c|c|c|}
\hline \multirow{11}{*}{ China } & & & $0.221[1]$ & & & \\
\hline & & $0.187[2]^{* *}$ & & $-0.085[0]^{* * *}$ & $-0.010[0]^{* *}$ & $-0.157 * *$ \\
\hline & & $0.152[3]^{* *}$ & & $-0.026[3]^{*}$ & $-0.012[3]^{*}$ & \\
\hline & & & & $-0.030[5]^{* * *}$ & $-0.020[4]^{* * *}$ & \\
\hline & & & & $-0.036[7]^{* * *}$ & $-0.024[5]^{* * *}$ & \\
\hline & & & & $-0.056[8]^{* * *}$ & $-0.216[6]^{* * *}$ & \\
\hline & & & & $-0.066[10]^{* * *}$ & $-0.009[17]^{* *}$ & \\
\hline & & & & $-0.026\left[12^{*}\right.$ & & \\
\hline & & & & $-0.033[14]^{* * *}$ & & \\
\hline & & & & $-0.020[15]^{*}$ & & \\
\hline & & & & $-0.038[16]^{* * *}$ & & \\
\hline \multirow[t]{11}{*}{ Colombia } & $0.283[3]^{* * *}$ & $0.184[2]^{* * *}$ & $0.315[1]^{* *}$ & $-0.071[15]^{* * *}$ & $-0.027[3]^{* * *}$ & $-0.097 * *$ \\
\hline & & $0.063[3]^{* *}$ & $0.883[2] * * *$ & $-0.032[16]^{* * *}$ & $-0.021[4]^{* *}$ & \\
\hline & & $0.059[5]^{* * *}$ & $1.198[3]^{* * *}$ & & $-0.036[5]^{* * *}$ & \\
\hline & & & $0.735[4] * * *$ & & $-0.029[6]^{* *}$ & \\
\hline & & & & & $-0.046[7]^{* * *}$ & \\
\hline & & & & & $-0.028[9]^{* * *}$ & \\
\hline & & & & & $-0.015[11]^{*}$ & \\
\hline & & & & & $-0.027[1]^{* * *}$ & \\
\hline & & & & & $-0.038[13]^{* * *}$ & \\
\hline & & & & & $-0.015[14]^{*}$ & \\
\hline & & & & & $-0.022[15]^{* *}$ & \\
\hline \multirow{6}{*}{$\begin{array}{l}\text { Czech } \\
\text { Republic }\end{array}$} & $0.175[3]^{* *}$ & & $0.330[1]^{* * *}$ & $-0.027[9]^{* *}$ & $-0.036[5]^{* *}$ & $-0.111 * * *$ \\
\hline & & & $0.415[2]^{* * *}$ & $-0.035[16]^{* * *}$ & & \\
\hline & & & $0.557[3]^{* * *}$ & & & \\
\hline & & & $0.152[7]^{* *}$ & & & \\
\hline & & & $0.124[8]^{*}$ & & & \\
\hline & & & $0.156[9] * * *$ & & & \\
\hline \multirow[t]{8}{*}{ Denmark } & & $0.068[1]^{* * *}$ & $0.495[7]^{*}$ & $-0.242[0] * * *$ & $-0.146[1]^{* * *}$ & -0.055 \\
\hline & & $0.072[2]^{* * *}$ & & $-0.115[5]^{* *}$ & $-0.118[2]^{* * *}$ & \\
\hline & & & & $-0.118[6]^{* *}$ & $-0.113[7]^{* * *}$ & \\
\hline & & & & $-0.136[9]^{* *}$ & $-0.104[10]^{* * *}$ & \\
\hline & & & & $-0.269[10]^{* * *}$ & $-0.087[11]^{* * *}$ & \\
\hline & & & & $-0.126[11]^{*}$ & $-0.072[13]^{* * *}$ & \\
\hline & & & & $-0.196[13]^{* * *}$ & $-0.097[14]^{* * *}$ & \\
\hline & & & & & $-0.046[16]^{*}$ & \\
\hline \multirow[t]{10}{*}{ Finland } & & $0.018[2]^{* *}$ & $0.601[1]^{* * *}$ & $-0.051[5]^{*}$ & $-0.033[7]^{*}$ & $-0.190 * * *$ \\
\hline & & & $0.565[2] * * *$ & $-0.055[7]^{* *}$ & $-0.030[8]^{*}$ & \\
\hline & & & $0.753[3] * * *$ & $-0.037[16]^{* *}$ & $-0.023[11]^{*}$ & \\
\hline & & & $0.766[4] * * *$ & & $-0.039[12]^{* * *}$ & \\
\hline & & & $0.541[5] * * *$ & & $-0.064[13]^{* * *}$ & \\
\hline & & & $0.419[6]^{* * *}$ & & $-0.080[14]^{* * *}$ & \\
\hline & & & $0.287[7]^{* *}$ & & $-0.061[15]^{* * *}$ & \\
\hline & & & $0.404[8] * * *$ & & $-0.043[16]^{* * *}$ & \\
\hline & & & $0.341[9]^{* * *}$ & & $-0.022[17]^{* *}$ & \\
\hline & & & $0.201[10]^{* * *}$ & & $-0.020[18]^{* * *}$ & \\
\hline Hong & $0.260[1]^{*}$ & $0.075[0]^{*}$ & $0.756[1]^{* *}$ & $-0.131[1]^{* *}$ & & $-0.214^{* *}$ \\
\hline \multirow[t]{6}{*}{ Kong } & & $0.132[3]^{* * *}$ & $0.423[8]^{* *}$ & $-0.188[4]^{* *}$ & & \\
\hline & & & $0.367[9]^{*}$ & $-0.233[8] * * *$ & & \\
\hline & & & $0.275[10]^{* *}$ & $-0.123[11]^{* *}$ & & \\
\hline & & & & $-0.080[13]^{* *}$ & & \\
\hline & & & & $-0.151[14]^{* *}$ & & \\
\hline & & & & $-0.199[16]^{* * *}$ & & \\
\hline \multirow[t]{8}{*}{ Indonesia } & & $0.070[2]^{* *}$ & $0.244[1]^{* *}$ & $-0.079[2]^{* * *}$ & $-0.036[1]^{* * *}$ & $-0.225 * * *$ \\
\hline & & & $0.418[2] * * *$ & $-0.079[4]^{* * *}$ & & \\
\hline & & & $0.961[3]^{* * *}$ & $-0.080[5] * * *$ & & \\
\hline & & & $0.557[4]^{* * *}$ & $-0.074[7]^{* * *}$ & & \\
\hline & & & $0.498[5] * * *$ & $-0.073[8]^{* * *}$ & & \\
\hline & & & & $-0.060[11]^{* * *}$ & & \\
\hline & & & & $-0.035[12]^{* *}$ & & \\
\hline & & & & $-0.024[14]^{*}$ & & \\
\hline
\end{tabular}




\begin{tabular}{|c|c|c|c|c|c|c|}
\hline \multirow{11}{*}{ Ireland } & & & & $-0.036[16]^{* * *}$ & & \\
\hline & \multirow[t]{10}{*}{$0.310[1]^{* * *}$} & & $0.576[1]^{* * *}$ & $-0.042[3]^{* * *}$ & $-0.015[1]^{* *}$ & $-0.220 * * *$ \\
\hline & & & $0.357[2]^{* * *}$ & $-0.024[7]^{*}$ & $-0.012[6]^{* *}$ & \\
\hline & & & $0.334[3] * * *$ & $-0.053[12]^{* * *}$ & $-0.023[7]^{* * *}$ & \\
\hline & & & $0.249[4]^{* *}$ & & $-0.016[8]^{* *}$ & \\
\hline & & & $0.290[5] * * *$ & & $-0.021[9]^{* * *}$ & \\
\hline & & & $0.177[6]^{*}$ & & $-0.015[10]^{* *}$ & \\
\hline & & & $0.174[7] * *$ & & $-0.020[11]^{* * *}$ & \\
\hline & & & & & $-0.022[12]^{* * *}$ & \\
\hline & & & & & $-0.014[13]^{* *}$ & \\
\hline & & & & & $-0.014[15]^{* * *}$ & \\
\hline \multirow[t]{7}{*}{ Italy } & & $0.044[0]^{* * *}$ & $-0.392[9]^{*}$ & $-0.079[3]^{* *}$ & $-0.089[7]^{* * *}$ & $-0.285 * * *$ \\
\hline & & $0.059[2]^{* * *}$ & & $-0.151[5]^{* * *}$ & $-0.110[12]^{* * *}$ & \\
\hline & & $0.045[3]^{* * *}$ & & $-0.106[9]^{* * *}$ & $-0.043[13]^{* *}$ & \\
\hline & & & & $-0.081[13]^{* *}$ & $-0.044[14]^{* *}$ & \\
\hline & & & & & $-0.038[15]^{* *}$ & \\
\hline & & & & & $-0.039[16]^{* *}$ & \\
\hline & & & & & $-0.039[17]^{* *}$ & \\
\hline \multirow[t]{19}{*}{ Japan } & $0.322[1] * * *$ & $0.011[5]^{* * *}$ & $0.524[1]^{* * *}$ & $-0.004[10]^{* * *}$ & $-0.026[0]^{* * *}$ & $-0.824 * * *$ \\
\hline & $0.490[2] * * *$ & & $0.670[2]^{* * *}$ & $-0.002[16]^{* *}$ & $-0.022[1] * * *$ & \\
\hline & $0.596[3]^{* * *}$ & & $0.753[3]^{* * *}$ & & $-0.015[2]^{* * *}$ & \\
\hline & & & $0.131[4]^{* *}$ & & $-0.021[3]^{* * *}$ & \\
\hline & & & $0.094[5]^{*}$ & & $-0.030[4]^{* * *}$ & \\
\hline & & & $0.067[7]^{*}$ & & $-0.026[5]^{* * *}$ & \\
\hline & & & $0.072[8] * *$ & & $-0.018[6]^{* * *}$ & \\
\hline & & & $0.067[9]^{* * *}$ & & $-0.019[7]^{* * *}$ & \\
\hline & & & $0.038[10]^{* * *}$ & & $-0.021[8] * * *$ & \\
\hline & & & & & $-0.021[9]^{* * *}$ & \\
\hline & & & & & $-0.015[10]^{* * *}$ & \\
\hline & & & & & $-0.013[11]^{* * *}$ & \\
\hline & & & & & $-0.018[12]^{* * *}$ & \\
\hline & & & & & $-0.013[13]^{* * *}$ & \\
\hline & & & & & $-0.005[14]^{* *}$ & \\
\hline & & & & & $-0.006[15]^{* * *}$ & \\
\hline & & & & & $-0.014[16]^{* * *}$ & \\
\hline & & & & & $-0.011[17]^{* * *}$ & \\
\hline & & & & & $-0.005[18]^{* * *}$ & \\
\hline \multirow[t]{12}{*}{ Malaysia } & $0.246[1]^{* * *}$ & $0.005[0]^{*}$ & $0.374[1]^{* * *}$ & $-0.006[4]^{*}$ & $-0.007[7]^{* *}$ & $-0.180 * * *$ \\
\hline & $0.548[3]^{* * *}$ & $0.012[1] * * *$ & $0.542[3] * * *$ & $-0.021[5] * * *$ & $-0.019[8] * * *$ & \\
\hline & & & & $-0.012[8] * * *$ & $-0.025[9]^{* * *}$ & \\
\hline & & & & $-0.035[9]^{* * *}$ & $-0.018[10]^{* * *}$ & \\
\hline & & & & $-0.013[10]^{* * *}$ & $-0.029[11]^{* * *}$ & \\
\hline & & & & $-0.026[11]^{* * *}$ & $-0.022[12]^{* * *}$ & \\
\hline & & & & $-0.008[12]^{* *}$ & $-0.013[13]^{* * *}$ & \\
\hline & & & & $-0.015[13]^{* * *}$ & $-0.008[14]^{* * *}$ & \\
\hline & & & & $-0.020[15]^{* * *}$ & $-0.017[15]^{* * *}$ & \\
\hline & & & & & $-0.011[16]^{* * *}$ & \\
\hline & & & & & $-0.006[17]^{* * *}$ & \\
\hline & & & & & $-0.004[18]^{* * *}$ & \\
\hline \multirow[t]{13}{*}{ Mexico } & $0.598[1]^{* * *}$ & $0.142[3]^{* * *}$ & $1.183[1]^{* * *}$ & $-0.033[0]^{* *}$ & $-0.098[3]^{* * *}$ & $-0.493 * * *$ \\
\hline & & $0.110[5]^{* *}$ & $0.748[2]^{* * *}$ & $-0.040[8]^{* *}$ & $-0.208[4] * * *$ & \\
\hline & & & $0.715[3]^{* * *}$ & $-0.050[9]^{* * *}$ & $-0.212[5] * * *$ & \\
\hline & & & $0.576[4]^{* * *}$ & $-0.062[12]^{* * *}$ & $-0.144[6] * * *$ & \\
\hline & & & $0.534[5]^{* * *}$ & $-0.035[16]^{* *}$ & $-0.117[7]^{* *}$ & \\
\hline & & & $0.569[6]^{* * *}$ & & $-0.132[8] * * *$ & \\
\hline & & & $0.448[7]^{* * *}$ & & $-0.082[11]^{* *}$ & \\
\hline & & & $0.573[8] * *$ & & $-0.086[12]^{* * *}$ & \\
\hline & & & $0.364[9]^{* * *}$ & & $-0.113[13]^{* * *}$ & \\
\hline & & & $0.254[10]^{* *}$ & & $-0.071[14]^{* *}$ & \\
\hline & & & & & $-0.102[15]^{* * *}$ & \\
\hline & & & & & $-0.078[16]^{* * *}$ & \\
\hline & & & & & $-0.062[17]^{* *}$ & \\
\hline
\end{tabular}




\begin{tabular}{|c|c|c|c|c|c|c|}
\hline & & & & & $-0.062[18]^{* *}$ & \\
\hline New & $1.057[1] * * *$ & $0.028[0]^{* *}$ & $1.099[1]^{* * *}$ & $-0.025[1]^{* * *}$ & $-0.012[0]^{* * *}$ & $-0.1676^{* * *}$ \\
\hline \multirow[t]{14}{*}{ Zealand } & & $0.083[1] * * *$ & $0.180[8]^{*}$ & $-0.025[10]^{* *}$ & $-0.023[1]^{* * *}$ & \\
\hline & & $0.037[2]^{* *}$ & $0.233[9]^{* * *}$ & $-0.026[11]^{* *}$ & $-0.018[2]^{* *}$ & \\
\hline & & $0.064[4] * * *$ & & $-0.024[12]^{* *}$ & $-0.019[3]^{* *}$ & \\
\hline & & $0.076[5] * * *$ & & $-0.023[14]^{* *}$ & $-0.040[4]^{* * *}$ & \\
\hline & & & & & $-0.034[5]^{* * *}$ & \\
\hline & & & & & $-0.047[6]^{* * *}$ & \\
\hline & & & & & $-0.053[7]^{* * *}$ & \\
\hline & & & & & $-0.034[9]^{*}$ & \\
\hline & & & & & $-0.039[10]^{*}$ & \\
\hline & & & & & $-0.054[11]^{* * *}$ & \\
\hline & & & & & $-0.038[12]^{* *}$ & \\
\hline & & & & & $-0.055[13]^{* * *}$ & \\
\hline & & & & & $-0.046[14]^{* * *}$ & \\
\hline & & & & & $-0.020[16]^{*}$ & \\
\hline \multirow[t]{5}{*}{ Philippines } & $0.193[2]^{*}$ & $0.067[0]^{*}$ & $0.288[1]^{*}$ & $-0.054[1]^{* * *}$ & $-0.025[13]^{* * *}$ & $-0.251 * * *$ \\
\hline & $0.424[3]^{* * *}$ & $0.137[1] * * *$ & $0.407[2] * * *$ & $-0.038[4]^{*}$ & $-0.020[15]^{* * *}$ & \\
\hline & & & $0.810[3]^{* * *}$ & $-0.035[10]^{* *}$ & $-0.017[17]^{* * *}$ & \\
\hline & & & $0.329[7]^{* * *}$ & $-0.048[11]^{* * *}$ & $-0.015[18]^{* * *}$ & \\
\hline & & & $0.203[8]^{*}$ & $-0.043[12]^{*}$ & & \\
\hline \multirow[t]{5}{*}{ Poland } & $0.562[1]^{* * *}$ & & $0.986[1]^{* * *}$ & & $-0.031[6]^{*}$ & $-0.231 * * *$ \\
\hline & & & $0.604[2] * * *$ & & $-0.042[8]^{* *}$ & \\
\hline & & & $0.412[3]^{*}$ & & $-0.039[11]^{* * *}$ & \\
\hline & & & $0.495[4]^{* * *}$ & & $-0.026[15]^{*}$ & \\
\hline & & & & & $-0.048[17]^{* *}$ & \\
\hline \multirow[t]{7}{*}{ Russia } & & $0.115[3]^{* *}$ & & $-0.109[1]^{* *}$ & $-0.132[0]^{* * *}$ & -0.037 \\
\hline & & $0.144[4] * * *$ & & $-0.185[2]^{* * *}$ & $-0.116[1] * * *$ & \\
\hline & & & & $-0.161[10]^{* *}$ & $-0.103[9]^{* * *}$ & \\
\hline & & & & $-0.183[11]^{* *}$ & $-0.084[10]^{*}$ & \\
\hline & & & & $-0.154[12]^{*}$ & $-0.153[11]^{* * *}$ & \\
\hline & & & & $-0.214[13]^{* * *}$ & $-0.055[13]^{*}$ & \\
\hline & & & & & $-0.107[18]^{* * *}$ & \\
\hline \multirow[t]{4}{*}{ Singapore } & & $0.045[1]^{* * *}$ & $0.227[4]^{*}$ & $-0.111[1]^{* * *}$ & & $-0.259 * * *$ \\
\hline & & $0.031[4] * *$ & & $-0.087[2]^{*}$ & & \\
\hline & & & & $-0.086[11]^{* *}$ & & \\
\hline & & & & $-0.115[14]^{* * *}$ & & \\
\hline South & & $0.540[1]^{* * *}$ & $0.207[1]^{* * *}$ & $-0.048[0]^{* * *}$ & $-0.037[0]^{* * *}$ & $0.222 * * *$ \\
\hline \multirow[t]{13}{*}{ Africa } & & $0.124[2] * * *$ & $0.668[2]^{* * *}$ & $-0.013[2] * * *$ & $-0.118[1]^{* * *}$ & \\
\hline & & $0.449[3]^{* * *}$ & $1.458[4]^{* * *}$ & $-0.015[3]^{* * *}$ & $-0.050[2] * * *$ & \\
\hline & & $0.240[4] * * *$ & $1.214[5]^{* * *}$ & $-0.056[4]^{* * *}$ & $-0.020[3]^{* * *}$ & \\
\hline & & & $0.711[6]^{* * *}$ & $-0.012[5]^{* * *}$ & $-0.017[4] * * *$ & \\
\hline & & & $0.343[10]^{* * *}$ & $-0.082[6] * * *$ & $-0.026[6]^{* * *}$ & \\
\hline & & & & $-0.090[7]^{* * *}$ & $-0.015[9]^{* * *}$ & \\
\hline & & & & $-0.056[8]^{* * *}$ & $-0.016[10]^{* * *}$ & \\
\hline & & & & $-0.098[9]^{* * *}$ & $-0.002[14]^{* * *}$ & \\
\hline & & & & $-0.067[10]^{* * *}$ & $-0.025[15]^{* * *}$ & \\
\hline & & & & $-0.080[12]^{* * *}$ & $-0.018[16]^{* * *}$ & \\
\hline & & & & $-0.006[13]^{* * *}$ & & \\
\hline & & & & $-0.026[14]^{* * *}$ & & \\
\hline & & & & $-0.105[16]^{* * *}$ & & \\
\hline South & $0.540[1]^{* * *}$ & $0.048[0]^{* * *}$ & $0.883[1]^{* * *}$ & $-0.020[11]^{* * *}$ & $-0.006[0]^{*}$ & $-0.068 * * *$ \\
\hline \multirow[t]{7}{*}{ Korea } & & $0.058[1] * * *$ & $0.370[3]^{* * *}$ & & $-0.024[1] * * *$ & \\
\hline & & & $0.238[4]^{* * *}$ & & $-0.012[2]^{* *}$ & \\
\hline & & & $0.314[6]^{* * *}$ & & $-0.008[4]^{*}$ & \\
\hline & & & $0.212[8]^{* * *}$ & & $-0.008[8]^{* *}$ & \\
\hline & & & $0.156[9]^{* * *}$ & & $-0.019[9]^{* * *}$ & \\
\hline & & & $0.070[10]^{* *}$ & & $-0.011[13]^{* * *}$ & \\
\hline & & & & & $-0.015[16]^{* * *}$ & \\
\hline Spain & $0.510[1]^{* * *}$ & & $0.796[1]^{* * *}$ & $-0.096[12]^{* * *}$ & $-0.027[9]^{* *}$ & $-0.228 * * *$ \\
\hline & & & & & $-0.058[14]^{* * *}$ & \\
\hline & & & & & $-0.027[16]^{*}$ & \\
\hline
\end{tabular}




\begin{tabular}{|c|c|c|c|c|c|c|}
\hline \multirow[t]{5}{*}{ Sweden } & $0.316[1]^{*}$ & $0.030[0]^{* * *}$ & $0.700[1]^{* * *}$ & $-0.054[8]^{* *}$ & & -0.017 \\
\hline & $0.452[3]^{*}$ & $0.012[5]^{*}$ & $0.593[3]^{* * *}$ & $-0.028[10]^{*}$ & & \\
\hline & & & $0.121[10]^{*}$ & $-0.060[11] * * *$ & & \\
\hline & & & & $-0.046[13]^{*}$ & & \\
\hline & & & & $-0.041[15]^{* *}$ & & \\
\hline \multirow[t]{17}{*}{ Switzerland } & $0.214[2]^{* * *}$ & & $0.440[1]^{* * *}$ & $-0.024[0]^{* *}$ & $-0.039[0]^{* * *}$ & $-0.516 * * *$ \\
\hline & & & $0.647[2]^{* * *}$ & $-0.049[4]^{* * *}$ & $-0.044[1]^{* * *}$ & \\
\hline & & & $0.650[3] * * *$ & $-0.065[5] * * *$ & $-0.078[2]^{* * *}$ & \\
\hline & & & $0.331[4]^{* *}$ & $-0.043[13]^{* * *}$ & $-0.088[3]^{* * *}$ & \\
\hline & & & $0.371[5] * * *$ & $-0.062[14] * * *$ & $-0.079[4]^{* * *}$ & \\
\hline & & & $0.372[6]^{* * *}$ & $-0.056[16]^{* * *}$ & $-0.090[5]^{* * *}$ & \\
\hline & & & $0.330[7] * * *$ & & $-0.127[6]^{* * *}$ & \\
\hline & & & $0.367[8]^{* * *}$ & & $-0.121[7]^{* * *}$ & \\
\hline & & & $0.465[9] * * *$ & & $-0.108[8]^{* * *}$ & \\
\hline & & & & & $-0.077[9]^{* * *}$ & \\
\hline & & & & & $-0.097[10]^{* * *}$ & \\
\hline & & & & & $-0.078[11]^{* * *}$ & \\
\hline & & & & & $-0.093[12]^{* * *}$ & \\
\hline & & & & & $-0.064[13]^{* * *}$ & \\
\hline & & & & & $-0.041[14]^{* *}$ & \\
\hline & & & & & $-0.036[15]^{* *}$ & \\
\hline & & & & & $-0.023[16]^{*}$ & \\
\hline \multirow[t]{10}{*}{ Thailand } & $0.289[1]^{* *}$ & & $0.714[1]^{* * *}$ & $-0.022[4]^{*}$ & $-0.007[4]^{* *}$ & $-1.079 * * *$ \\
\hline & $0.361[2]^{* * *}$ & & $0.869[2]^{* * *}$ & $-0.016[8]^{*}$ & $-0.011[5]^{* * *}$ & \\
\hline & & & $0.370[3]^{* *}$ & $-0.014[14]^{*}$ & $-0.007[6]^{* *}$ & \\
\hline & & & $0.402[4]^{* * *}$ & & $-0.018[7]^{* * *}$ & \\
\hline & & & $0.319[5]^{* * *}$ & & $-0.008[8]^{* *}$ & \\
\hline & & & $0.254[6] * * *$ & & $-0.011[14]^{* * *}$ & \\
\hline & & & $0.178[7] * * *$ & & $-0.011[15]^{* * *}$ & \\
\hline & & & & & $-0.009[16]^{* *}$ & \\
\hline & & & & & $-0.015[17]^{* * *}$ & \\
\hline & & & & & $-0.010[18]^{* * *}$ & \\
\hline Turkey & & $1.521[4]^{*}$ & & & $-0.593[7]^{* *}$ & -0.338 \\
\hline \multirow{8}{*}{$\begin{array}{l}\text { United } \\
\text { Kingdom }\end{array}$} & & $0.083[1]^{* *}$ & $0.733[9]^{* * *}$ & $-0.068[9]^{* * *}$ & $-0.041[3]^{* * *}$ & 0.045 \\
\hline & & & $0307[10] * * *$ & & & \\
\hline & & $0.097[4]^{* * *}$ & & $-0.064[12]^{* * *}$ & $-0.092[5] * * *$ & \\
\hline & & $0.108[5]^{* * *}$ & & $-0.045[14]^{* *}$ & $-0.102[6]^{* * *}$ & \\
\hline & & & & $-0.037[15]^{* *}$ & $-0.114[7]^{* * *}$ & \\
\hline & & & & & $-0.133[8]^{* * *}$ & \\
\hline & & & & & $-0.109[9]^{* * *}$ & \\
\hline & & & & & $-0.103[10]^{* *}$ & \\
\hline \multirow{6}{*}{$\begin{array}{l}\text { United } \\
\text { States }\end{array}$} & $0.498[1]^{* * *}$ & $0.162[0]^{* * *}$ & $0.771[1]^{* * *}$ & $-0.046[3]^{* * *}$ & $-0.042[3]^{* *}$ & $-0.092 * * *$ \\
\hline & & $0.157[1]^{* * *}$ & $0.342[8]^{* * *}$ & $-0.029[6]^{*}$ & $-0.068[10]^{* * *}$ & \\
\hline & & & $0.307[9]^{* * *}$ & $-0.065[10]^{* * *}$ & $-0.025[15]^{*}$ & \\
\hline & & & $0.172[10]^{* * *}$ & $-0.027[12]^{*}$ & $-0.029[17]^{* * *}$ & \\
\hline & & & & $-0.049[14] * * *$ & & \\
\hline & & & & $-0.033[15]^{*}$ & & \\
\hline
\end{tabular}

Notes: $* * *, * *$ and $*$ denotes the significance level at the $1 \%, 5 \%$ and $10 \%$, respectively. Data are collected from year 1995 quarter one until year 2018 quarter one. The bracket denotes the lag length. ${ }^{\text {b}}$ This paper only reports those results from the variables which have the correct expected sign and are significant.

Table A.2

Estimation of PMG results for 30 countries, individually, from year 1995 quarter one to year 2018 quarter one using standard Taylor rule model 


\begin{tabular}{|c|c|c|c|c|}
\hline \multirow[t]{2}{*}{ Countries } & \multicolumn{4}{|c|}{ Variables } \\
\hline & $r_{g_{t}}$ coef. $^{\mathrm{b}}$ & $y_{g_{t}}$ coef. ${ }^{b}$ & $\pi_{g_{t}}$ coef. & EC coef. \\
\hline Argentina & $0.321[3]^{*}$ & & $0.784[0]^{*}$ & $-0.433 * * *$ \\
\hline \multirow[t]{3}{*}{ Australia } & $0.639[1]^{* * *}$ & $0.036[5]^{*}$ & $0.577[1]^{* * *}$ & $-0.283 * * *$ \\
\hline & & & $0.139[8]^{* *}$ & \\
\hline & & & $0.127[9]^{* *}$ & \\
\hline Brazil & $0.541[1] * * *$ & & & $-0.426 * * *$ \\
\hline Canada & $0.576[1]^{* * *}$ & & $0.600[1]^{* * *}$ & $-0.195 * * *$ \\
\hline China & $0.239[3]^{* *}$ & $0.331[5]^{* *}$ & & $-0.500 * * *$ \\
\hline \multirow[t]{8}{*}{ Colombia } & $0.452[1] * * *$ & $0.118[4]^{*}$ & $0.773[1]^{* * *}$ & $-0.161^{* *}$ \\
\hline & & & $1.287[2]^{* * *}$ & \\
\hline & & & $0.707[3]^{* *}$ & \\
\hline & & & $0.733[4]^{* *}$ & \\
\hline & & & $1.132[5] * * *$ & \\
\hline & & & $0.985[7]^{* * *}$ & \\
\hline & & & $0.686[8]^{* *}$ & \\
\hline & & & $0.667[9]^{* * *}$ & \\
\hline \multirow[t]{3}{*}{ Czech Republic } & $0.146[1]^{*}$ & & $0.328[1] * * *$ & $-0.182 * * *$ \\
\hline & $0.161[2] * * *$ & & $0.380[2]^{* * *}$ & \\
\hline & & & $0.285[3] * * *$ & \\
\hline Denmark & & & & $-0.798^{* * *}$ \\
\hline \multirow[t]{4}{*}{ Finland } & $0.227[1]^{* *}$ & & $0.562[1]^{* * *}$ & $-0.220^{* * *}$ \\
\hline & & & $0.454[2]^{* * *}$ & \\
\hline & & & $0.298[3]^{*}$ & \\
\hline & & & $0.223[6]^{* *}$ & \\
\hline Hong Kong & & & & $-0.260 * * *$ \\
\hline \multirow{6}{*}{ Indonesia } & $0.124[3]^{*}$ & $0.198[0]^{* *}$ & $0.675[1]^{* * *}$ & $-0.288^{* * *}$ \\
\hline & & $0.163[5]^{*}$ & $0.669[2]^{* * *}$ & \\
\hline & & & $0.422[3]^{* * *}$ & \\
\hline & & & $0.441[5]^{* * *}$ & \\
\hline & & & $0.368[7]^{* * *}$ & \\
\hline & & & $0.221[10]^{* * *}$ & \\
\hline \multirow[t]{3}{*}{ Ireland } & $0.256[1]^{* *}$ & & $0.475[1]^{* * *}$ & $-0.118 * * *$ \\
\hline & & & $0.221[2]^{*}$ & \\
\hline & & & $0.221[3]^{*}$ & \\
\hline \multirow[t]{2}{*}{ Italy } & & $0.025[3]^{*}$ & $0.380[1]^{*}$ & $-0.279 * * *$ \\
\hline & & & $0.532[9]^{* *}$ & \\
\hline \multirow[t]{3}{*}{ Japan } & $0.339[1]^{* * *}$ & $0.008[0]^{* *}$ & $0.310[1] * * *$ & -0.056 \\
\hline & & $0.007[2]^{*}$ & & \\
\hline & & $0.010[3]^{* * *}$ & & \\
\hline \multirow[t]{2}{*}{ Malaysia } & $0.373[1]^{* * *}$ & & $0.309[1]^{* * *}$ & $-0.205 * * *$ \\
\hline & $0.256[3]^{* *}$ & & & \\
\hline \multirow[t]{9}{*}{ Mexico } & $0.841[1]^{* * *}$ & $0.178[3]^{* *}$ & $1.080[1]^{* * *}$ & $-0.586^{* * *}$ \\
\hline & $0.441[3]^{* * *}$ & $0.255[5] * * *$ & $1.145[3]^{* * *}$ & \\
\hline & & & $0.497[4]^{*}$ & \\
\hline & & & $0.452[5]^{*}$ & \\
\hline & & & $0.564[6] * *$ & \\
\hline & & & $0.824[7]^{* * *}$ & \\
\hline & & & $1.077[8]^{* * *}$ & \\
\hline & & & $0.590[9]^{* * *}$ & \\
\hline & & & $0.693[10]^{* * *}$ & \\
\hline \multirow[t]{2}{*}{ New Zealand } & $0.514[1]^{* * *}$ & $0.102[2]^{* * *}$ & $0.400[1]^{* *}$ & $-0.224 * * *$ \\
\hline & $0.240[3]^{* * *}$ & $0.132[3]^{* * *}$ & & \\
\hline \multirow[t]{2}{*}{ Philippines } & $0.367[1] * * *$ & & & $-0.539 * * *$ \\
\hline & $0.196[3]^{* *}$ & & & \\
\hline \multirow[t]{5}{*}{ Poland } & $0.389[1]^{* * *}$ & & $0.758[1]^{* * *}$ & $-0.271 * * *$ \\
\hline & $0.268[2]^{* *}$ & & $0.504[2] * * *$ & \\
\hline & & & $0.3132[5]^{*}$ & \\
\hline & & & $0.371[7]^{* *}$ & \\
\hline & & & $0.253[8]^{*}$ & \\
\hline \multirow[t]{2}{*}{ Russia } & $0.785[2]^{* * *}$ & $0.216[4]^{*}$ & & $-0.649 * * *$ \\
\hline & $0.426[3]^{* * *}$ & & & \\
\hline
\end{tabular}




\begin{tabular}{|c|c|c|c|c|}
\hline Singapore & $0.255[2]^{* *}$ & & & $-0.349 * * *$ \\
\hline \multirow[t]{3}{*}{ South Africa } & $0.398[1]^{* * *}$ & & $0.457[1]^{* * *}$ & $-0.222 * * *$ \\
\hline & & & $0.183[9]^{*}$ & \\
\hline & & & $0.174[10]^{*}$ & \\
\hline \multirow[t]{5}{*}{ South Korea } & $0.445[1] * * *$ & & $0.515[0]^{* * *}$ & $-0.216 * *$ \\
\hline & & & $1.250[1] * * *$ & \\
\hline & & & $0.558[2]^{*}$ & \\
\hline & & & $0.528[4]^{*}$ & \\
\hline & & & $0.466[6]^{*}$ & \\
\hline \multirow[t]{2}{*}{ Spain } & $0.350[1]^{* * *}$ & & $0.365[1] * * *$ & $-0.194 * * *$ \\
\hline & $0.374[2] * * *$ & & $0.345[2]^{* *}$ & \\
\hline \multirow[t]{3}{*}{ Sweden } & $0.379[1] * * *$ & & $0.641[1] * * *$ & $-0.182 * * *$ \\
\hline & & & $0.346[3]^{* *}$ & \\
\hline & & & $0.217[6]^{*}$ & \\
\hline Switzerland & & & & -0.029 \\
\hline \multirow[t]{3}{*}{ Thailand } & $0.508[1]^{* * *}$ & $0.107[1]^{* * *}$ & $0.409[1]^{* * *}$ & $-0.333 * * *$ \\
\hline & $0.235[2] * * *$ & & $0.233[2]^{*}$ & \\
\hline & & & $0.328[6]^{* * *}$ & \\
\hline \multirow[t]{2}{*}{ Turkey } & $0.496[1] * *$ & & $1.459[8]^{*}$ & $-0.977 * * *$ \\
\hline & & & $1.625[9]^{* *}$ & \\
\hline \multirow[t]{4}{*}{ United Kingdom } & $0.282[1] * * *$ & $0.091[0]^{*}$ & $0.327[1]^{*}$ & $-0.250 * * *$ \\
\hline & & $0.112[2]^{* *}$ & $0.429[8]^{* *}$ & \\
\hline & & $0.089[3]^{* *}$ & & \\
\hline & & $0.097[5]^{* *}$ & & \\
\hline \multirow[t]{2}{*}{ United States } & $0.511[1]^{* * *}$ & & $0.541[1]^{* * *}$ & $-0.132 * * *$ \\
\hline & & & $0.113[9]^{*}$ & \\
\hline
\end{tabular}

Notes: $* * *, * *$ and $*$ denotes the significance level at the $1 \%, 5 \%$ and $10 \%$, respectively. Data are collected from year 1995

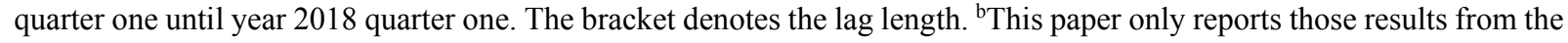
variables which have the correct expected sign and are significant.

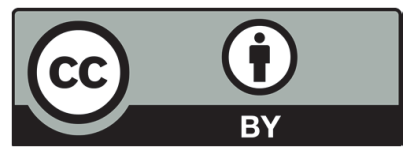

(C) 2019 by the authors; licensee Growing Science, Canada. This is an open access article distributed under the terms and conditions of the Creative Commons Attribution (CCBY) license (http://creativecommons.org/licenses/by/4.0/). 